\title{
الاتفاقيات بين المساهمين في شركة المساهمة
}

\author{
أ ـ أ عبد الباقي خلفاوي \\ كلية الحقوق تلفي \\ جامعة قسنطينة 1 الحنوف
}

مقدّمة:

شركة المساهمة هي شركة تجارية

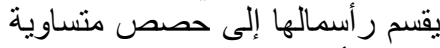

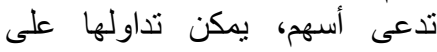

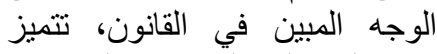

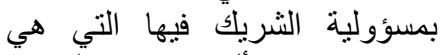
محدودة، فلا يسأل عن ديون التشركة

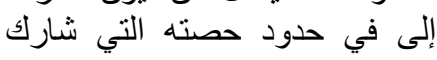

وتعد شركات المساهمة

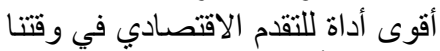

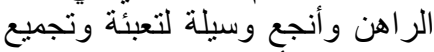

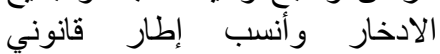
للمقاو لات الكبرى، وقد حظيت هذه

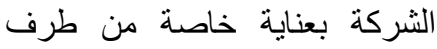

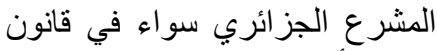
1975،أو المرسوم الجزئ

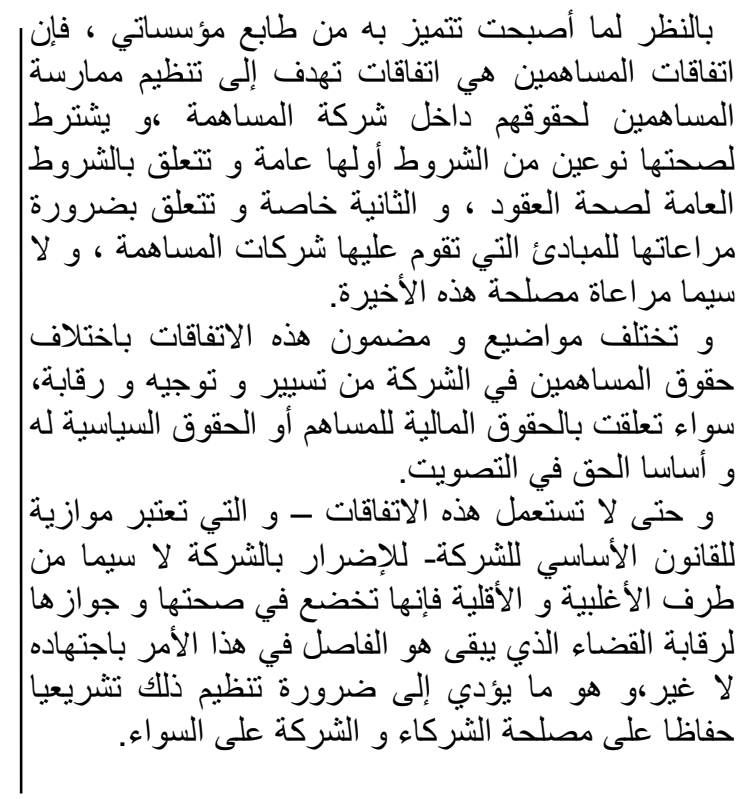

Résumé :

Les conventions entre actionnaires ou les les pactes d'actionnaires ce sont des contrats visent à réglementer les droits des actionnaires d'une société par actions, et son objet varie selon le type de droits auxquels ils se rapportent, si les droits financiers, ou le droit de contrôler, les droits de gestion et les droits politiques tels que le droit de vote.

Et est nécessaire pour la validité du convention la présence des conditions du contrat et quelle ne contredisent pas avec le statu fondamental de la société d'une part, et le respect des principes de la société par action et l'intérêt sociale de la société d'une autre part .

la légitimité des pactes d'actionnaires et toujours l'objet de la jurisprudence, car les lois des différents pays n'a pas mis une réglementation complète, et y compris le législateur algérien, que nous appelons à l'organisation de ces conventions , car ces accords et un moyen d'atténuer le caractère institutionnel des société par action, et d'encourager l'investissement. 


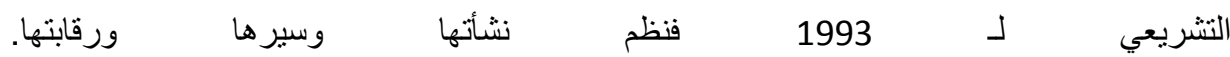

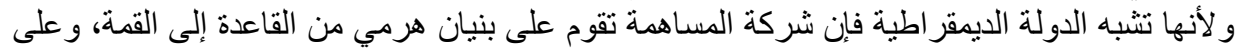

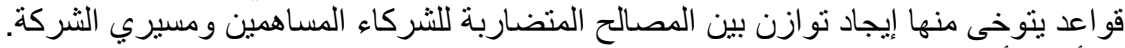

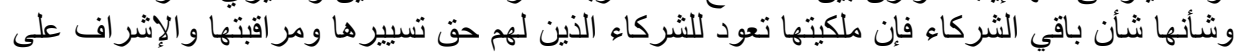

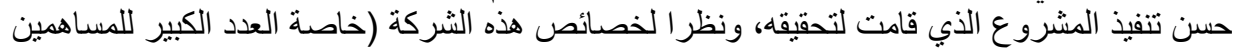

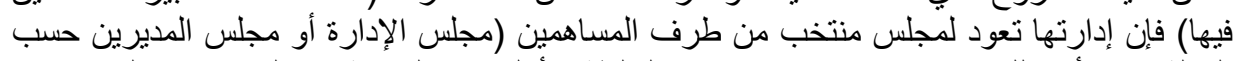

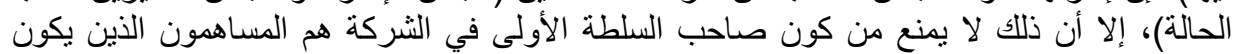

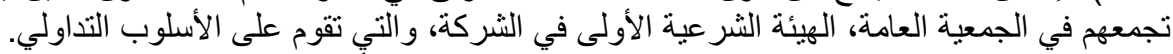

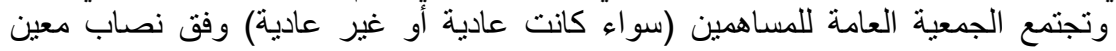

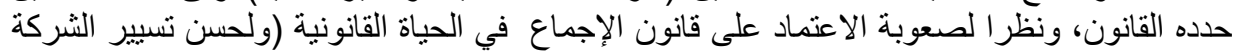

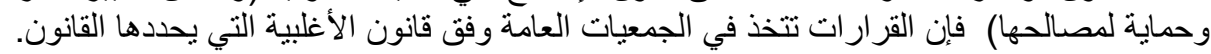

إلا أن تطبيق قانون الأغلبية الذي يثكل قرينة على إتباع المصلحة الاجتماعية للشركة يؤدي

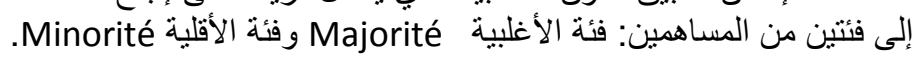

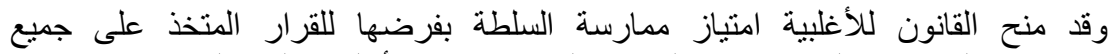

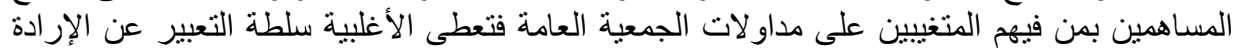

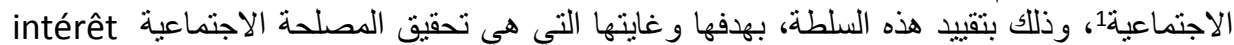
social للشركة، بالنظر لعدد الأشخاص و الحصص الششاركة في اتخاذ هذا القرار.

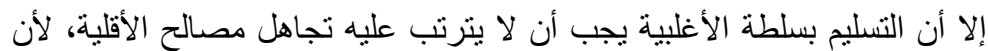

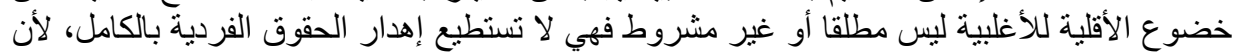

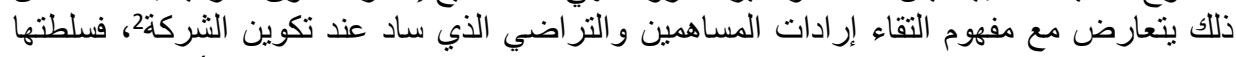

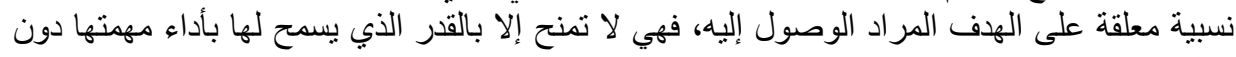
تجاوز.

لهذه الأسباب ترى مختلف التشريعات ضرورة تعزيز وحماية الحقوق الفردية المساهم، التي

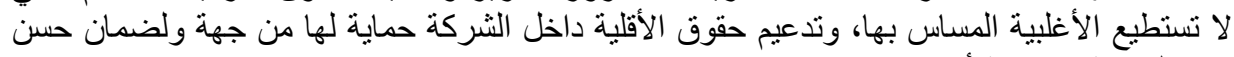

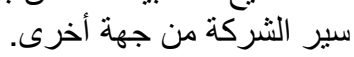

ولعل إبرام اتفاقات جانبية هي من أبرز الوسائل التي تسعى بواسطتها الأقلية تدعيم وحماية

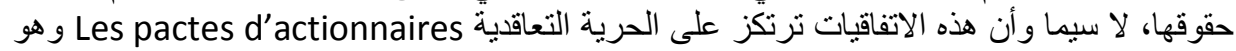

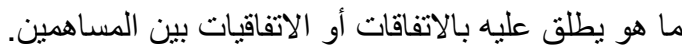

الاتفاقية بين المساهين هي اتفاق غالبا ما يكون سريا يعقد بين مساهين في الثركة سواء الثراء كانوا أغلبية أم أقلية، موضو عه تنظيم ورقابة حياة الثركة وحماية حقوق هذه الفئة من المساهمين.

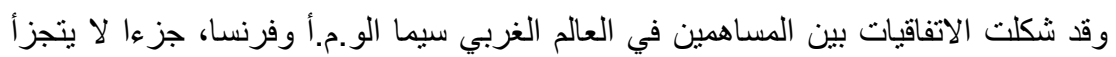

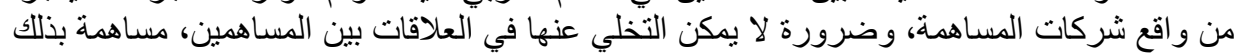

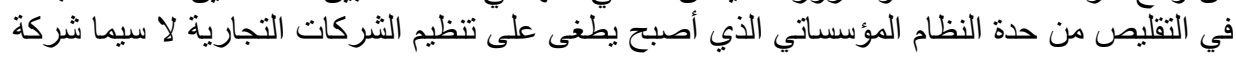
المساهمة.

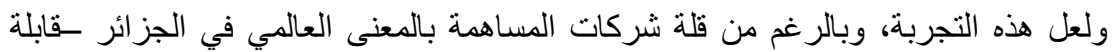

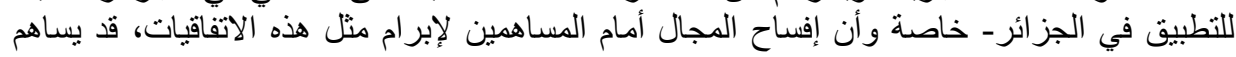


في تشجيع الاستثمار واستقطاب رؤوس الأموال، بدلا من أن تبقى شركاتتا ذات طابع عائلي محدود، غير قادرة على إدارة مشاريع اقتصادية ضخمة.

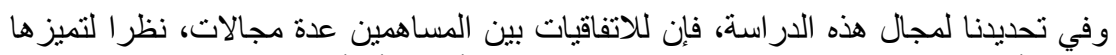

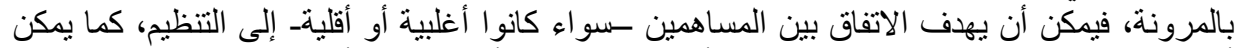

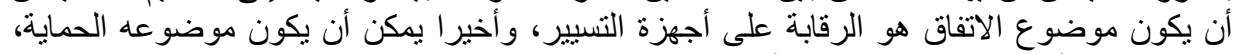

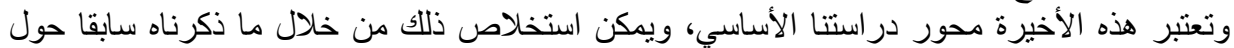
الأغلبية و الأقلية في شركات المساهمة.

فالاتفاقيات بين المساهمين هي وسيلة حماية هامة في يد المساهمين -خاصة الأقلية منهم-،

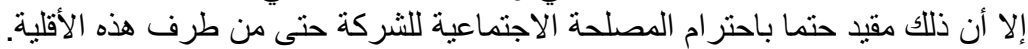

ولم يشر المشرع الجزائري في القانون التجاري المعدل والمتمم إلى هذه الاتفاقيات ولم

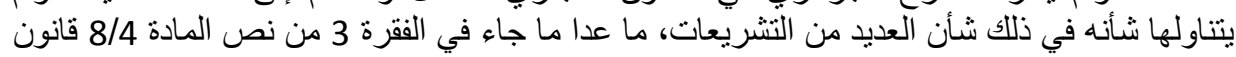

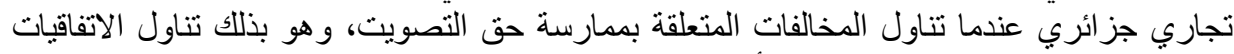

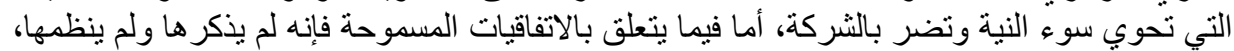
كماً أنه لم يحدد بدقة أسس التفريق بين النوعين.

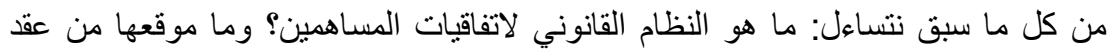
الثركة ونظامها الأساسي؟، ما مدى التوافق الموجود بين هذه الاتفاقيات والمصلحة الاجتماعية

هل نعتمد على مفهوم المخالفة من نص المادة 814 من القانون التجاري لمعرفة موقف

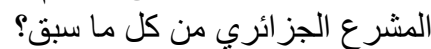

ولمعالجة ما سبق، نقسم دراستتا إلى قسمين نتناول في الأول النظام القانوني لاتفاقيات

المساهين، أما الثاني فنتناول فيه علاقة هذه الاتفاقيات بالمصلحة الاجتماعية للشركة. 
المبحث الأول: النظام القانونى لاتفاقيات المساهمين

باعتبار ها اتفاقات تقوم على الإدارة المنفردة والحرة للمساهمين فإننا نتساءل عن التكوين

القانوني لها وشروط صحتها وكذا تصنيفاتها (المطلب الأدارة المنفرد).

و لأنها تتميز بالمرونة مقارنة بعقد الثركة وقانونها الأساسي، وهو ما يجعلها جانبية بالنسبة

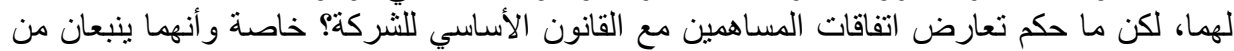
مصدر واحد وهو حرية الإدارة التعاقدية لدى المساهم (المطلاتب الثعان الثاني).

المطلب الأول: شروط صحة اتفاقيات المساهمين وتصنيفاتها

$$
\text { نتعرض لشروط الصحة في (فرع أول)، ثم لتصنيفات هذه الاتفاقات في (فرع ثاني). }
$$

الفرع الأول: شروط صحة اتفاقيات المساهمين

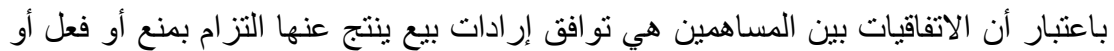

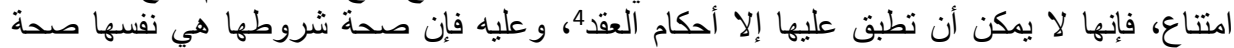
شروط العقد وفقا للشريعة العامة. لانئ.

وبالرجوع للمادة 53 وما بعدها من القانون المدني الجزائري فإن شروط الصحة هي:

ا- وجود وسلامة الرضا: إن إبرام أي اتفاق بين المساهمين يفترض توافق إرادات المشاركين

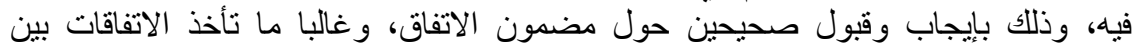

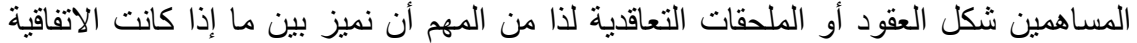
هي مجرد مفاوضات أو أنها و عد بالتعاقد أو عقد نهائي.

ويزداد الأمر صعوبة عندما تكون الاتفاقية مركبة أي تتضمن مجموعة التزامات من طبيعة مختلفة، يصعب معها تحديد العناصر الأساسية للاتفاقية أو العقد.

$$
\text { وفي كل الحالات فإنه يجب التمبيز بين مر احل عقد الاتفاقية كالآتي: }
$$

1- المرحلة التمهيدية: وهي مرحلة المفاوضات بين المساهمين حول مضمون الاتفاقية وآثار ها ومجال

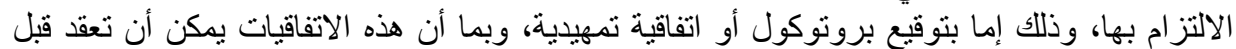

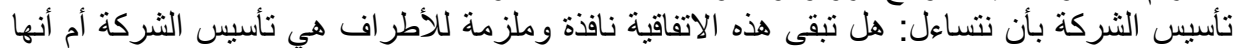

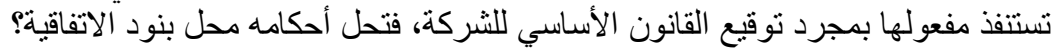

طرحت هذه المسألة أكثر من مرة على المحاكم الفرنسية، واعتبرت أن الأمر بتطلب تفسير

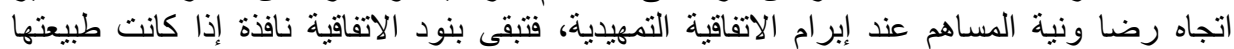
تقرض الاستمرار في تطبيقها.

وتفاديا لأي شك حول نية المساهمين الأطر اف وإر ادتهم، من المناسب أن تتضمن الاتفاقية التمهيدية نصا يفيد بأن بنودها تبقى نافذة وسارية المفعول بعد تأسيس الثركة.

2- مرحلة تكوين الاتفاقية وما بعدها: تطبق على الاتفاقية في هذه المرحلة نفس أحكام العقد المتعلقة

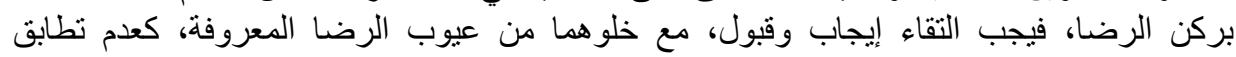


الإيجاب و القبول، والغلط الو اقع على موضوع الاتفاقية أو طبيعتها أو أطر افها، أو طبيعة الالتزامات

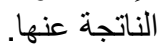

كذللك التدليس الحاصل من أحد أطراف الاتفاقية اتجاه الآخر، والذي من صوره صمت أحد

الأطراف اتجاه الآخر عن أمر لو علم به تراجع عن الاتفاقية6

ويعتبر الاجتهاد المتعلق بعيوب الرضا في اتفاقيات المساهمين نادرا جدا، غير أنه منشدد

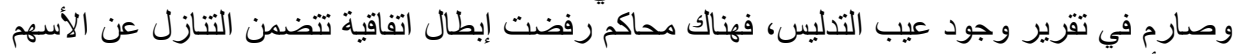

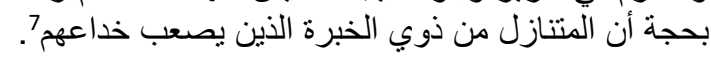

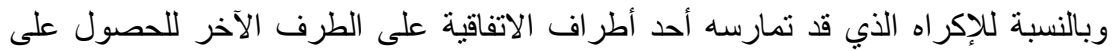

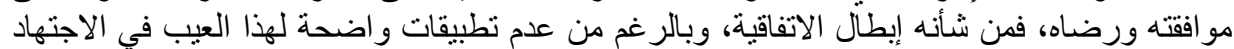
القضائي، إلا أن تحققه يكون أحد الأطراف تابعا اقتصاديا للطرف الآخر، بحيث نكون أُمام إكراه

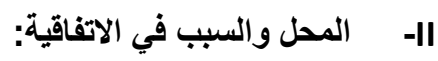

محل الاتفاقية هو موضوعها ويكون إما فعلا أو امتتاعا أو منحا، وذلك بنص المادة 53 ق.م.جن، ويشترط أن يكون المحل مشرو عا ومحددا تحديدا دقيقا وكأمنلة عن ذلكا ألك:

• في اتفاقية للتنازل عن الأسهم، يشترط تحديد ثمن السهم تحديدا دقيقا أو أن يكون قابلا للتقييم،

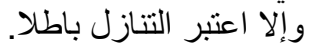

أما السبب فهو الدافع الذي حمل الأطر اف على إبر ام الاتفاقية فيجب أن يكون موجودا ومشروعاو.

فتعتبر باطلة الاتفاقية التي هدفها خلق أقلية عرقلة داخل الثركة Minorité de blocage،

ما يسبب ضررا للشركة.10.

ويحدد كل من محل الاتفاقية وسبيها بحسب نوعها باعتبار أنه وبالنظر لمرونتها فهي تحوي

عدة تصنيفات و أنو اع.

الفرع الثاني: أنواع الاتفاقيات بين المساهمين وتصنيفاتها

تنقسم الاتفاقيات بين المساهمين حسب مضمونها وما تعهذ أطر افها به، و وعليه تقسم الاتفاقيات

إلى اتفاقيات متعلقة بحصص الثركاء في الثركة (I) و إلى اتفاقيات منعلقة بتسيير الثركة (II).

\section{ا- الاتفاقيات المتعلقة بحصص الثركاء (الأسهر):}

هي اتفاقيات نهدف إما لنقل ملكية السهم أو ناقلة للحقوق المالية الملازمة له، وكأمثلة عنها نذكر:

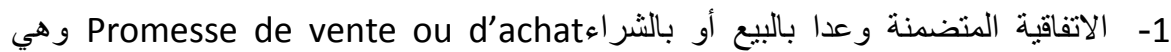

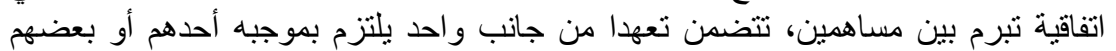

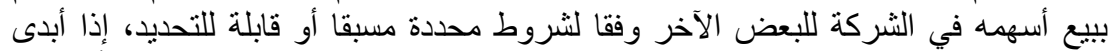

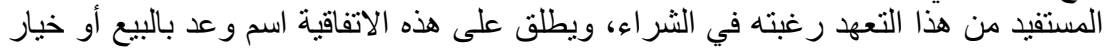

بالثر اء 
أما الاتفاقية التي تتضمن تعها من جانب واحد يلتزم بموجبه أحد أو بعض المساهمين بشر اء أسهر

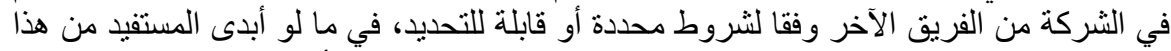

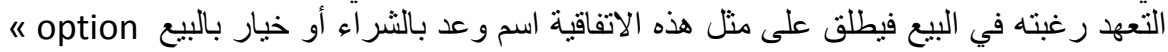

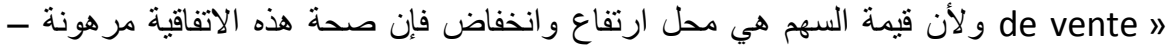

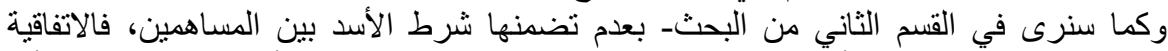

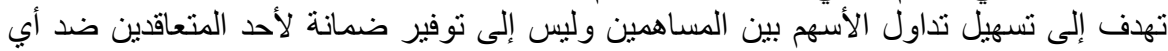

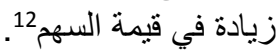

\section{2- اتفاقية شرط الحيازة Convention de portage:}

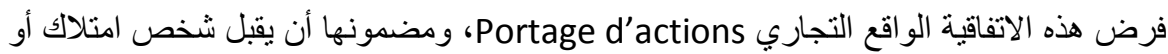

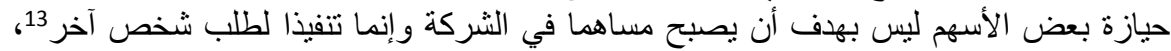
أي امتلاك أسهم لحساب شخص آخر يسترجعها هذا الأخير بانقضاء المهلة المتفق عليها و غالبا ما

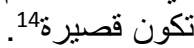

وشأنها شأن العديد من الاتفاقيات تعتبر هذه الاتفاقية عقدا غير مسمى تخضع لألأحكام العقود،

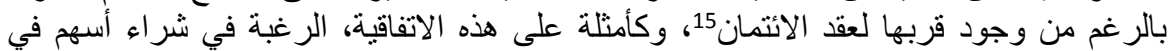

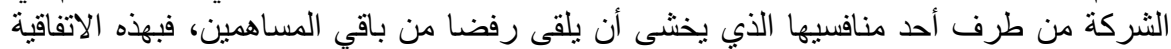

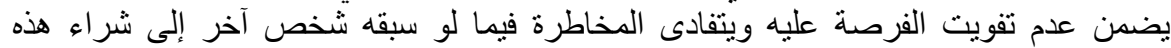

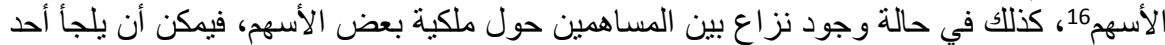

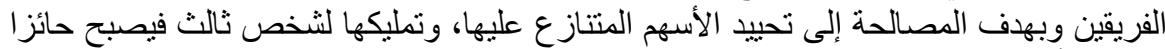
لهها، إلى أن يتوصلوا إلى حل لمشكلتهم.

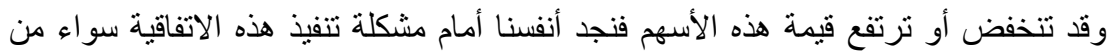

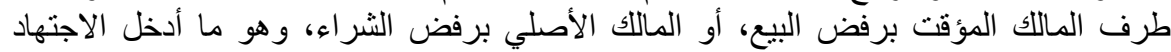
القضائي لا سيما الفرنسي في عدة خيار ات وحجج للتمسك بإلز امية هذه الاتفاقية.

\section{||- الاتفاقيات المتعلقة بالتسيير والإدارة:}

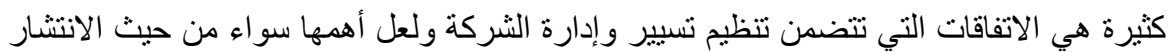

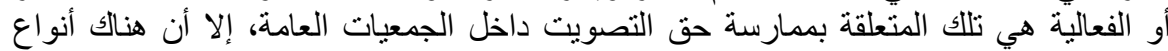

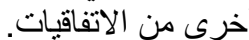

1- الاتفاقيات المتعلقة بأجهزة تسيير الثركة: وهي اتفاقيات مرتبطة إما بتعيين أعضاء الإدارة أو بعزلهم. أ- الاتفاقيات المرتبطة بتعيين أعضاء الإدارة:

قد يتفق المساهمون على اختيار أعضاء الأجهزة المسيرة، كاختيارهم من حملة بعض الأسهم أو من حملة عدد معين من الأسهم. 
كما يمكن أن يتم الاتفاق على توزيع عدد المناصب بهذف تأمين التمثيل المناسب في المجلس

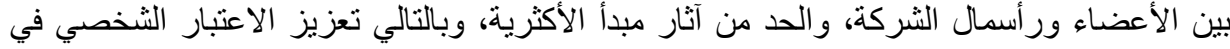
هذا النوع من الثركات

ويشترط في هذا النوع من الاتفاقيات، وكما سيتم تبيينه في القسم الثاني مر اعاة المبادئ التي التي

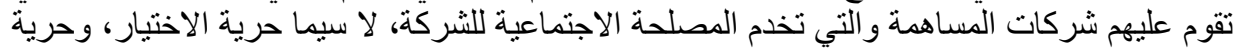

\section{ب- الاتفاقيات المرتبطة بعزل أعضاء الإدارة:}

تتص المادة 613 ق تجاري جزائري على إمكانية عزل أعضاء جلس الإدارة من طرف الجمعية العامة وفي أي وقت، و هو مبدأ من النظام العامعات.

ويمكن أن ترد الاتفاقية إما على كيفيات العزل أو على الحد من آثار عزل المديرين.

\section{2- الاتفاقيات المتعلقة بحق التصويت les conventions de vote:}

تعتبر من أهم وأبرز الاتفاقيات بين المساهمين و أكثرها خطورة وتأثير ا على حياة الثركة سواء وباء

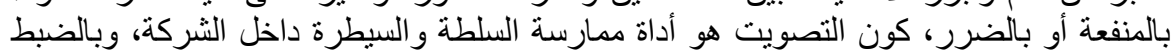
داخل هيئتها المداو لاتية الجمعية العامة.

و اتفاقات التصويت هي تلك الاتفاقيات التي يتعهد من خلالها مساهم أو عدة مساهمين ويلتزم

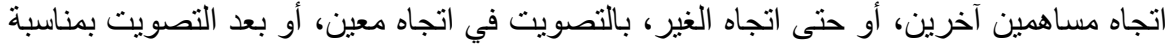
واحدة أو أكثر من القرارات آندان.

وتسمى أيضا اتفاقات تصويت، العقود التي يقوم فيها شريك أو مساهم ببيع، إيجار أو التنازل عن حقه في التصويت، مع الحفاظ على الحقوق المتصلة بالسهر.

وتعتبر أيضا اتفاقات تصويت تلك الاتفاقيات، سواء أكانت نظامية أم لا، التي تتعهد فيها

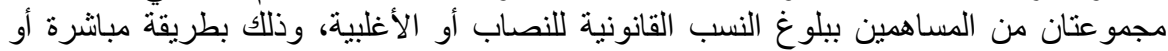
غير مبانشرة، وباتخاذ قرارات في الجمعيات العامة عن طريق اتفاق جماعي. وقد تطرق المشرع الجزائري لحق المساهم في التصويت في 674 وما بعدها من القانون التجاري الجز ائري عندما تناول جمعيات المساهمين.

$$
\text { و هل تجوز الاتفاقية الرامية إلى التنازل عن الحق في التصويت؟ }
$$

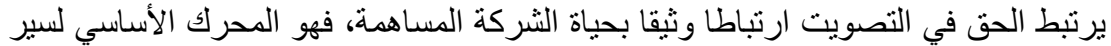

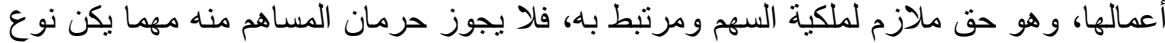

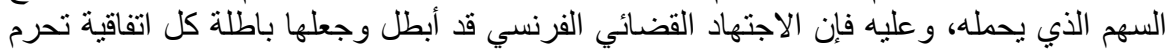

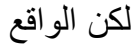
المساهم من حقه في التصويت.

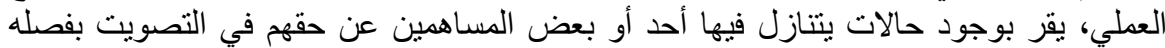

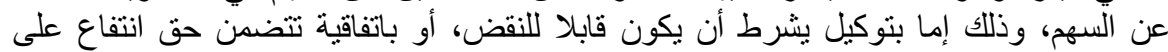

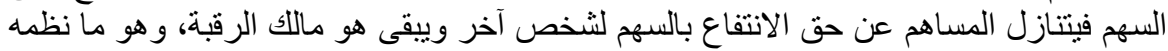


المشرع الجز ائري في المادة 679 قانون تجاري فأقر حق التصويت للمنتفع في الجمعيات العامة العادية، ولمالك الرقبة في الجمعيات العامة غير العادية فئرية

ولعل أهم نوع من أنواع اتفاقات التصويت والتي تساهل معها الاجتهاد القضائي و التي تعتبر

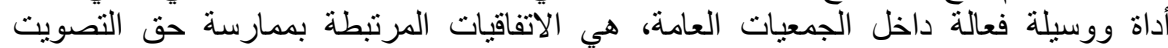

.$^{20}$ Convention relatives a l'exercice du droit de vote

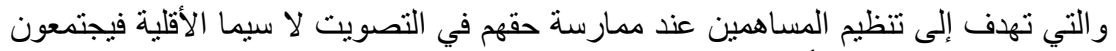

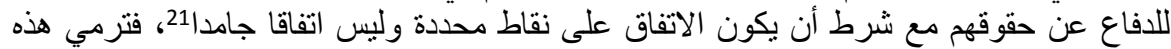

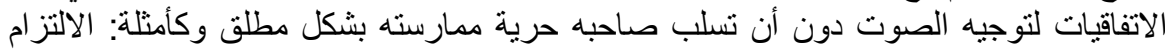
بالتصويت في مجلس الإدارة من أجل تسمية شخص معين لمركز الرئاسة.

وإذا كانت الاتفاقيات السابق ذكرها تهاف في مجملها إلى تنظيم حقوق المساهمين

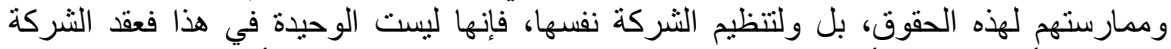
وقانونها الأساسي هي الأخرى قو اعد تنظم حياة وسير الثركة، فما علاقة الأولى بالثانية.

$$
\text { المطلب الثاني: الاتفاقيات بين المساهمين والقانون الأساسي للشركة }
$$

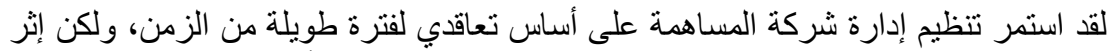

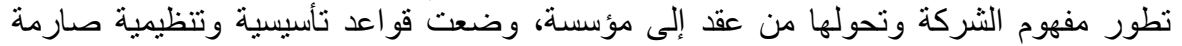
ودقيقة تحكم أدق التفاصيل في سير عمل الثركة.

ونتيجة لتذمر مساهمي الثركات والمتعاملين معها من هذه الصلابة حاولوا الهير الهروب

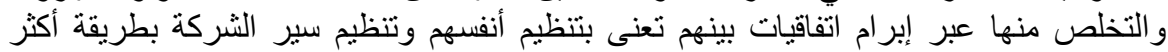

$$
\text { سهولة ويسرا. }
$$

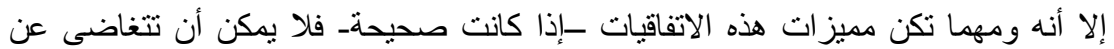

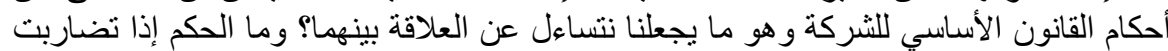
بنود اتفاقية مع القانون الأساسي للشركة اللشب؟

هنا يجب التمييز ما بين الاتفاقيات التي تتعارض أحكام القانون الأساسي وبين تلك التي تنظم مسائل لم يتناولها القانون الأساسي.

$$
\text { الفرع الأول: الاتفاقيات التي تتعارض و القانون الأساسي }
$$

يتضمن القانون الأساسي للثركة مجموعة قو اعد تختلف بحسب طبيعة ونوع الثركة منها

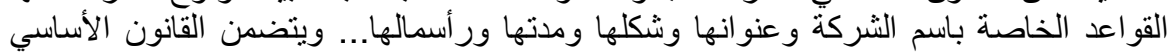
بالإضافة للقو اعد الإلزامية، قو اعد مكملة أو مفسرة للقو اعد القانونية.

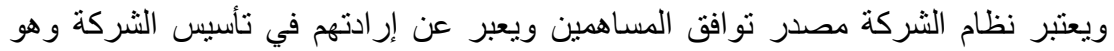

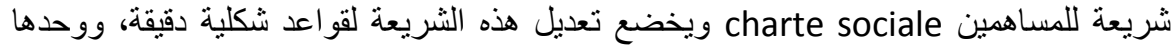
الجمعية العامة غير العادية صاحبة السلطة في إجراء هذا التعديل.

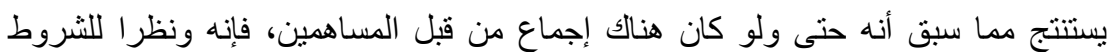
الثكلية المطلوبة فإن الاتفاقية الجانبية عاجزة عن تعديل القانون الأساسي فئ2. 


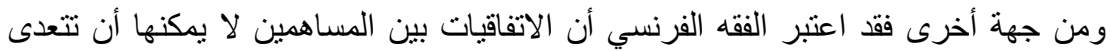

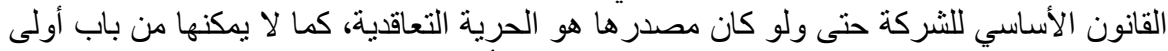

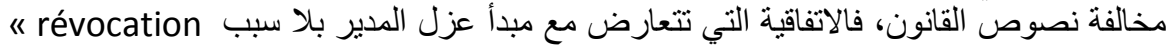

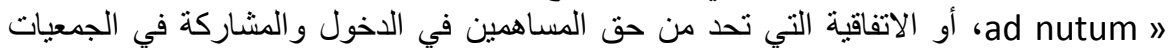

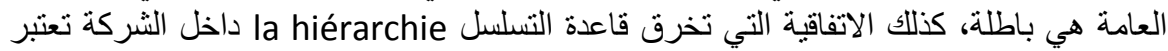

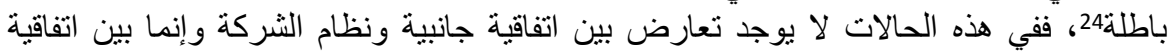
جانبية وقاعدة أساسية من قو اعد الثركة المساهمة، مما يفسد الطابع الجماعي لعقد الثركة.

ومن البديهي أن الاتفاقية لا تكسب أي قيمة إذا لم تكن مستقلة عن القانون الأساسي للشركة

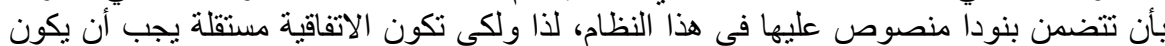

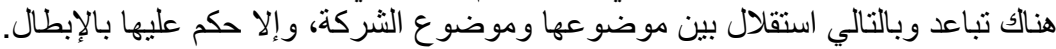

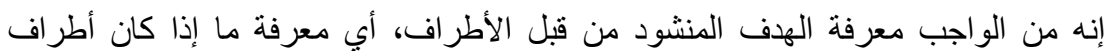

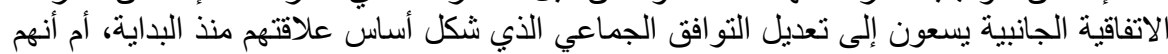

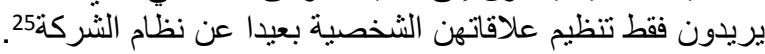

و وعليه عند رغبة المساهمين التفلت من تطبيق القواعد الإلزامية الخاصة بالثركات، فإنه يجب أن يلتزمو ا فضلا عن الثروط العامة لتكوين لتكن نطين العقود بأمرين:

الأول: ألا يتفقو ا على أمور سبق أن، اتفقو عليها في نظام الثركة تحت طائلة إبطال الاتفاقية. الثاني: ألا يتفقوا على أمور كان يفترض أن تدرج في النظام ولم يحصل ذلك، أو على أمور مخالفة لبنود مدرجة في النظام. الان القرع الثاني: الاتفاقيات التي تكمل القانون الأساسي وتنظم المساهمين

إن نظام الثركة بحتوي إلى جانب القواعد الإلزامية، على مجموعة مكملة ومفسرة للقو اعد التها

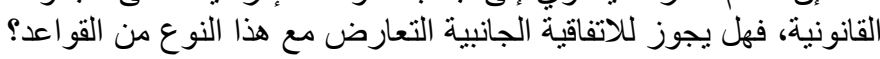

إن ما استقر عليه الفقه والقضاء هو جواز هذا التعارض ما دام هدف المساهمين هو إعادة

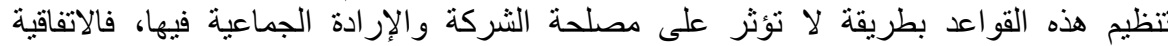
المرتبطة بتداول الأسهم، وبعزل المساهم لم تبطل من طرف الاجنتهاد القضائيك.

وكذلك الأمر بالنسبة للاتفاقية التي تتاولت مواضيع لم يتضمنها نظام الثركة، فقد أجاب

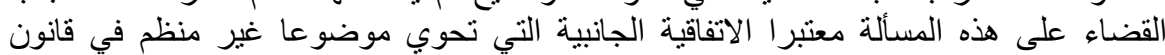
الثركة الأساسي، أو تتضمن بنودا مكملة له تعتبر صحيحة.

ويبقى وفي كل الحالات المعيار الأساسي والرئيسي لتحديد مدى صحة الاتفاقات بين الإنه

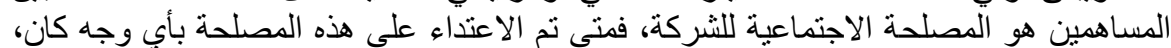
فإن البطلان سيكون لا محالة هو ما ستؤول إليه هذه الاتفاقية.

المبحث الثانى: الاتفاقيات بين المساهمين والمصلحة الاجتماعية للشركة

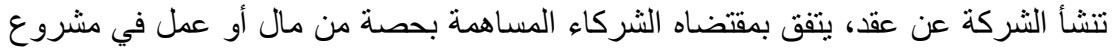

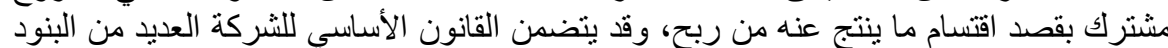




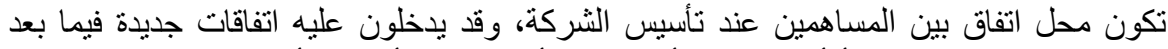

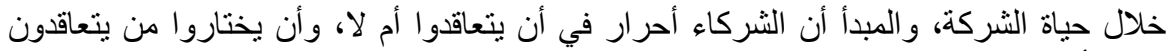

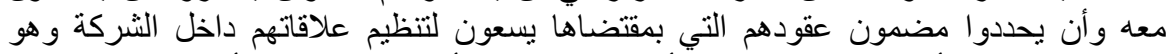

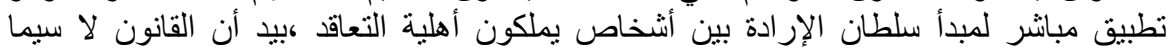

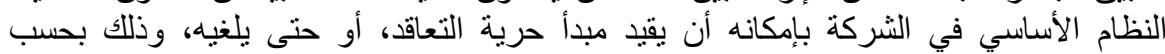

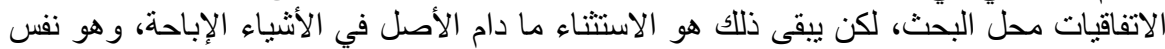

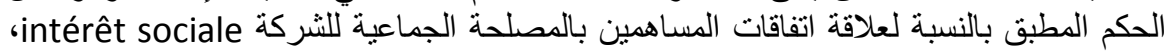

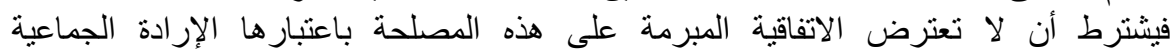

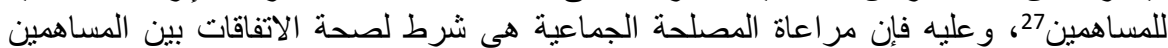

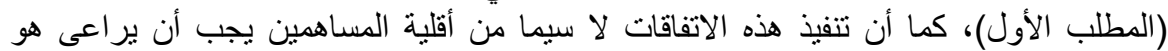
الآخر هذه المصلحة (المطلب الثاني).

المطلب الأول: المصلحة الاجتماعية وصحة الاتفاقيات بين المساهمين

لقد دخل الفقه و القضاء في جدل واسع حول تحديد مفهوم المصلحة الاجتماعية للشركة، بين

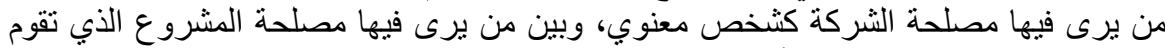

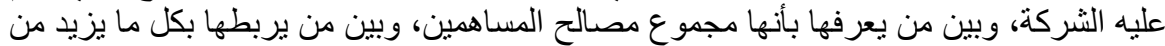

قوة الثركة من الناحية العطلية، وأخير الين من يوفق بين هذه النين النظريات في نظرية شاملة28.

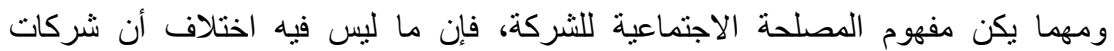

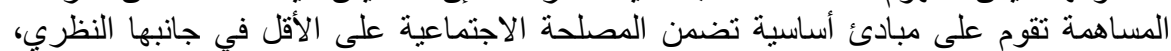

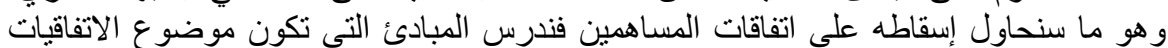

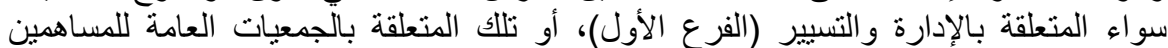

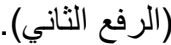

الفرع الأول: المبادئ المرتبطة بالإدارة والتسيير:

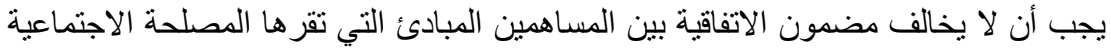
للشركة، والمتعلقة بإدارة الشركة وتنيير ها، ومن هذه المبادئ لذانكر:

\section{ا- I- مبلأ حرية الاختيار والعزل لأعضاء الإدارة:}

يقتضي هذا المبدأ أن المساهمين لهم الحرية الكاملة في اختيار من يسير الشركة، و لا يمكن

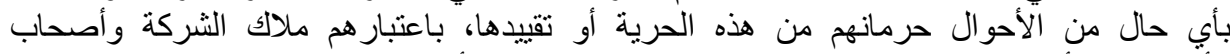

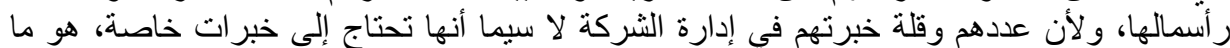
جعهم يوكلون تسيير ها لأعضاء آخرين، فالأصل أن الثريك هو الذي يدير الثير الثركة.

من جهة أخرى تملك المساهمون دائما، الحرية التامة و المطلقة في عزل أعضاء الإدارة وفي أي وقت، ودون إنذار مسبق، ودون تقرير الحق في التعويض.

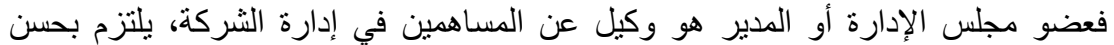

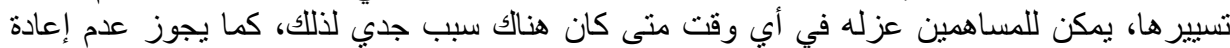


انتخابه، وكل اتفاق يحرم المساهم من هذا الحق أو يحد منه، فهو باطل باتفاق الفقه و القضاء، فهذا الحق هو الذي يخول المساهم ممارسة حق الرقابة داخل الثركة.

فتعتبر باطلة مثلا الاتفاقية التي يلتزم بموجبها أحد المساهمين بتعيين مساهم آخر من الأكثرية

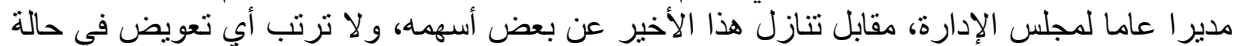

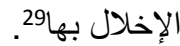

كنللك البند الذي يفرض نعاقب بعض الأثخاص على رئاسة مجلس الإدارة بعتبر باطلا،

كونه لا يترك للمساهمين حرية الاختيار، و هو تعدي مبدأ حرية التصويت ولئ ومبدأ عزل المديرين.

كما تم إبطال الاتفاقية التي التزمت بموجبها الأكثرية بتوجيه إنذار لرئيس مجلس الإدارة قبل سنة من قرار نوقيفه عن ممارسة عملهـان.

كما تم إبطال الاتفاقية التي تضمنت وعدا بتعيين أحد المساهمين مديرا فنبا، كتعويض عن عزله من مركزه كرئيس لمجلس إدارة الثركة.

وكذلك يعتبر باطلا كل شرط يخضع العزل لقرار يصدر عن الجمعية العامة غير العادية،

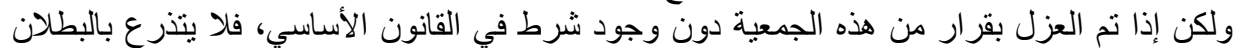

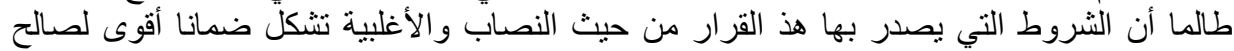

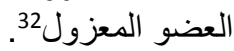

أما الاتفاقيات التي لا تضع حاجزا أمام مبدأ حرية العزل، وإنما تحاول التخفيف من آثاره،

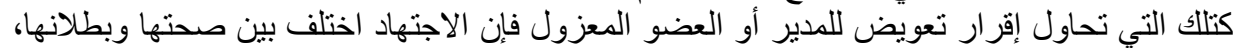
وذللك حسب درجة مساسها بحرية اختيار المساهم وحرية اتخاذ القرار.

||- |- مبدأ حرية تداول الأسهر:

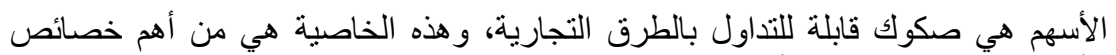

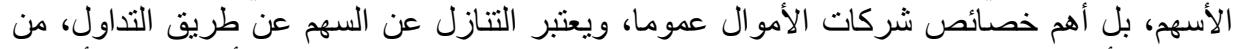

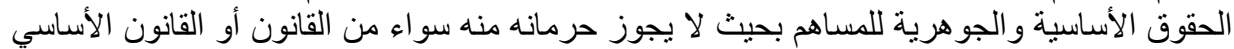
أو حتى الجمعية العامة غير العادية، ما عدا القيود التي يفرضها حرانها القانون في هذا التداول.

ويعتبر تنظيم تداول الأسهم من أكثر المواضيع التي تكون محلا لاتفاقات المساهمين، ويسري

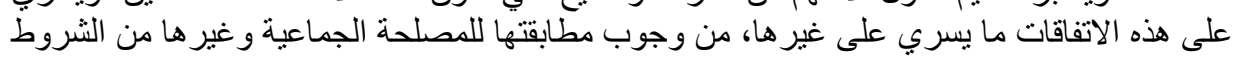
الضرورية لصحتها.

وقد كثر استعمال هذا النوع من الاتفاقيات لا سيما تلك التي تهدف إلى استقرار وتوزيع

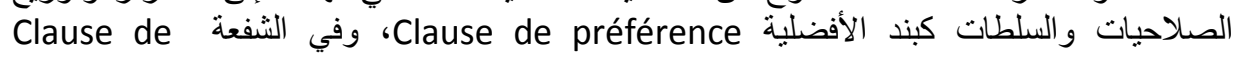

وبند الإذن أو شروط القبول préemption

وقد شدد الفقه بادئ الأمر في قبول مثل هذه الثروط، حيث أن تقييد تداول الأسهم يتجاهل

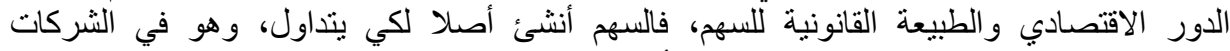

المساهمة بمثل الألية القانونية لتجميع رؤوس الأموال ولتركيز المشاريع.3. 


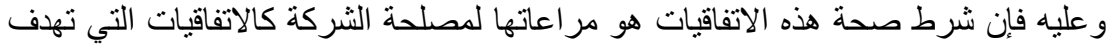

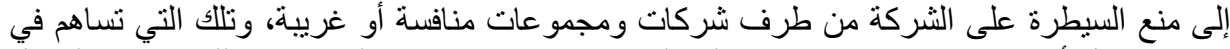

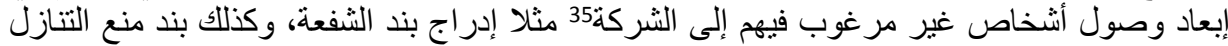

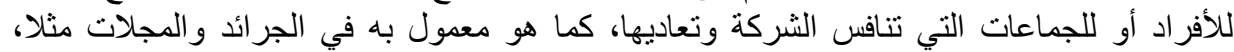

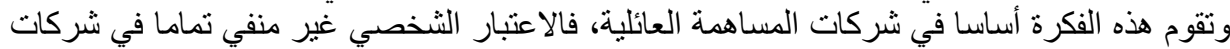
المساهمة، لكنه سلبي وليس إيجابي كما هو الحال في شركات الأشخاص، التي تعتمد على الآثخاص تُش

وتبقى رقابة القضاء سلاح هام وضروري، كونه يوازن بين مصلحة المساهم من جهة الإنة

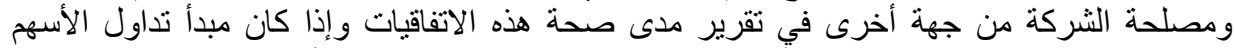

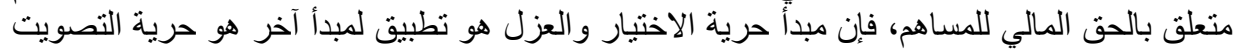

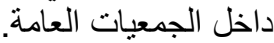

\section{الفرع الثاني: المبادئ المرتبطة بالتصويت في الجمعيات العامة}

إن الاتفاقيات حول التصويت، وكما سبق تعريفها، هي تلاك الاتفاقات التي بتعهد من خلال

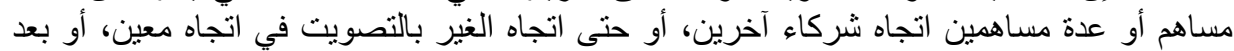
التصويت بمناسبة واحد أو أكثر من القرار شُاء آخرين.

وتتنكل اتفاقيات التصويت Conventions de vote من أبرز وأخطر أنواع الاتفاقات بين

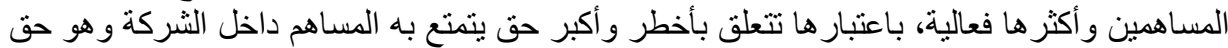

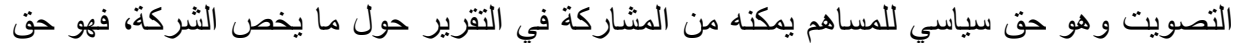

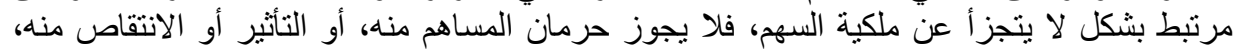

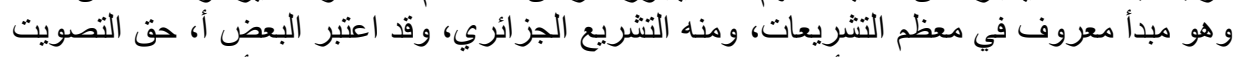

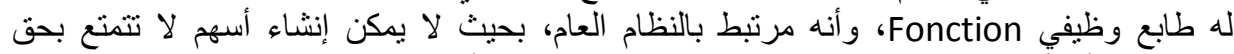

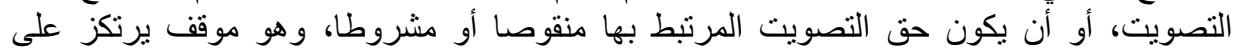

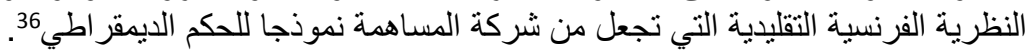

غير أن تدويل رأسمال الثركات وظاهرة تغيب المساهمين عن حضور جلسات الجمعيات

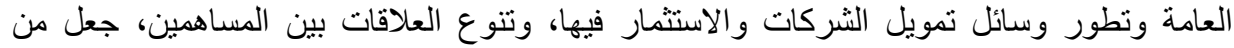

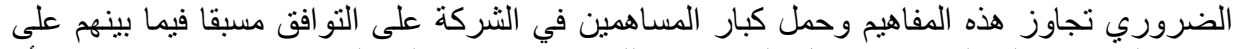

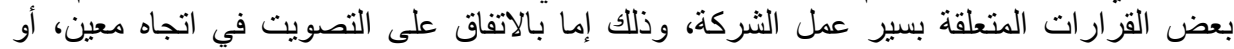

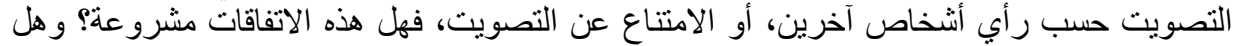

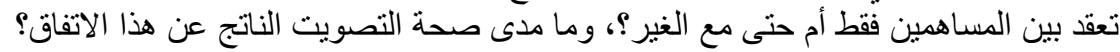

لقد اعتبر سوفي حالات كثبرة- أن الاتفاقات السابق ذكر ها تشكل اعتداءا وتهديد لمبدأ حرية

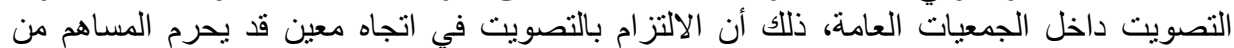

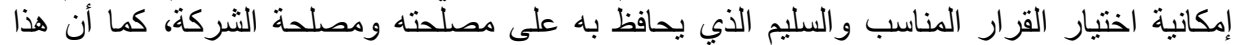

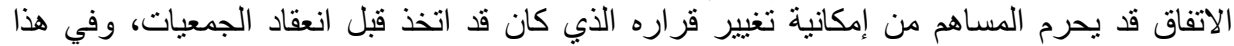

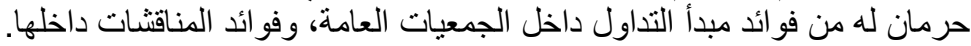

إضافة إلى ما سبق، فإن هذا النوع من الاتفاقات غالبا ما يقترن بسوء النية فغالبا ما يكون

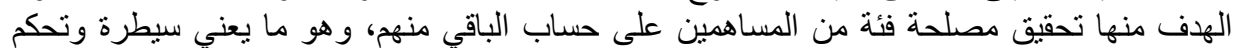
هذه الفئة في الثركة وفرضها لر أيها على الجماعة، وفي هذا اعتداء على مبدأ المساو اة بين المساهين. 
وبالرغم مها سبق فإن الفقه والقضاء قبلا بالمبدأ بمشروعية هذه الاتفاقات لكن المعيار

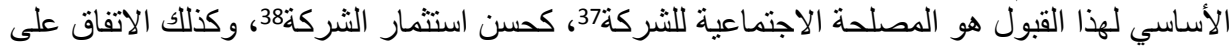
بند التعاقب Alternance في تعيين أعضاء مجلس الإدارة ورئيسهون.

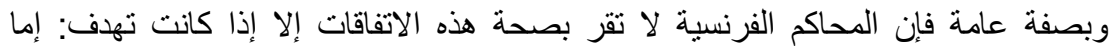

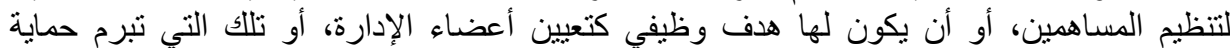

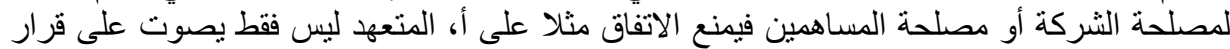

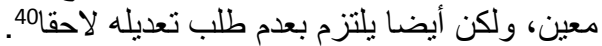

\section{• موقف التشريعات من اتفاقيات التصويت:}

لقد عزفت النصوص القانونية عن تنظيم هذه الاتفاقيات، فقد جاء المشرع الفرنسي سنة 1937

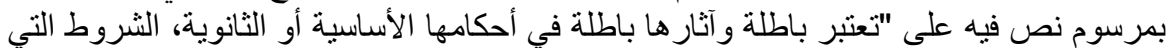
تهدف إلى المساس بحرية ممارسة الحق في التصويت داخل الجمعيات العامة للشركات التجارية التراية".

وقد نم استقبال هذا النص آنذاكل باستياء نوع ما، لأن تطبيقه حرفيا يؤدي إلى نتائج غير

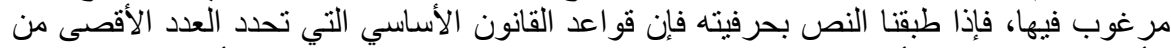

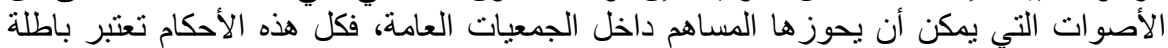

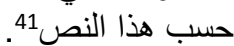

أما قانون 1966 فقد عدل هذا الاتجاه، نظر الما سبق ذكره، فلم ينص صراحة إنه على إجازة

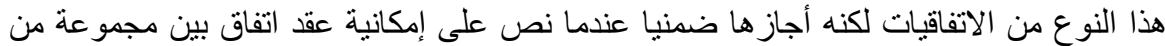

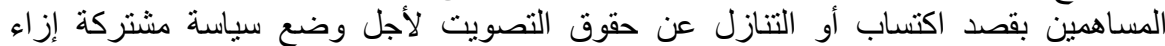

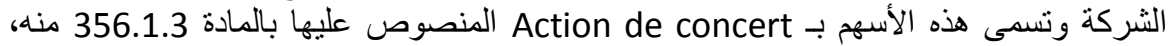

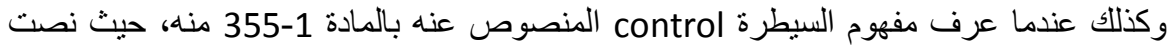

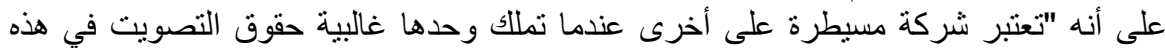

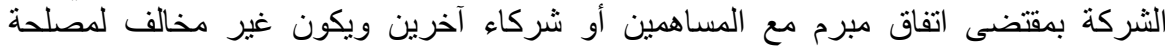

$$
\text { وهو اعتر اف ضمني بصحة مبدأ اتفاق التصويت42. }
$$

ونفس الأمر بالنسبة للمشرع الجزائري في المادة 814 فقرة 3 من القانون التجاري، حيث التيث

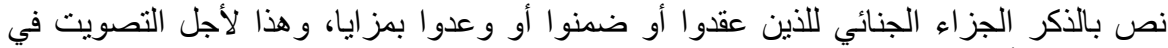

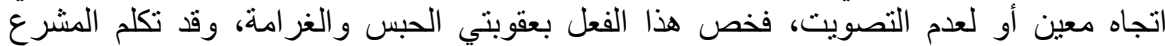
الجزائري هنا على الاتفاقيات التي تحوي سوء النية، أما الآتفاقات المسموحة فلم ينظمها.

ويختلف الحكم على مدى صحة اتفاقات التصويت، وكما سبق القول، بحسب مر اعاتها للمبادئ التي يقوم عليها هذا الحق، ولمدى مراعاة مصلحة الثركة، ويتغير نطاق هذا التهات الدفهوم حسب مضمون اتفاقيات التصويت المبرمة كالآتي: 


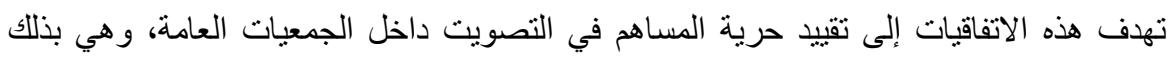

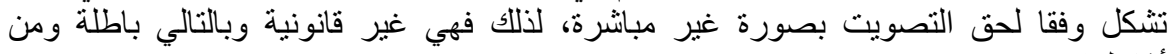
أشكالها: - n

الالتزام بالامتتاع عن التصويت أو التصويت حسب رأي الآخرين، أو الالتزام بعدم

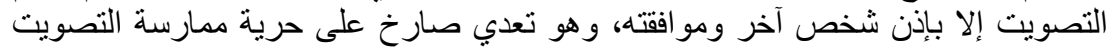

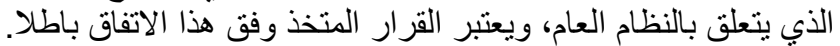

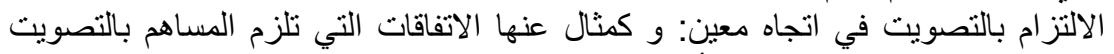

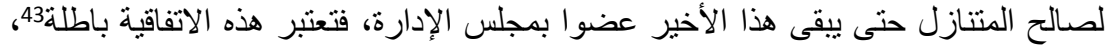

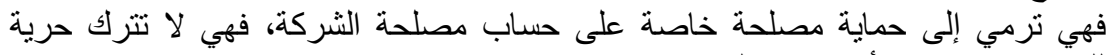

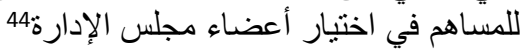
2- الاتفاقيات الموجهة لممارسة التصويت:

تهدف هذه الاتفاقيات إلى توجيه الصوت دون أن تسلب صاحبه حرية ممارسة بشكل مطلق، و وهي

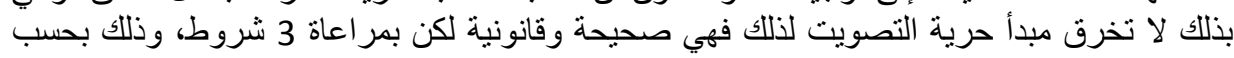

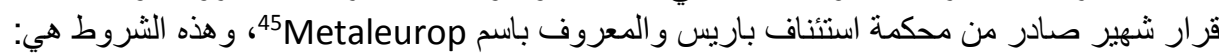

$$
\begin{aligned}
& \text { أ- أن يكون الاتفاق الموجه للتصويت مقيدا بعطلية واحدة. } \\
& \text { ب- أن يكون مطابقا للمصلحة الجماعية. }
\end{aligned}
$$

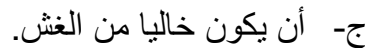

فالقضاء يطعن بصحة اتفاقات التصويت غير القابلة للنقض Irrévocables ولمدة غير محدودة

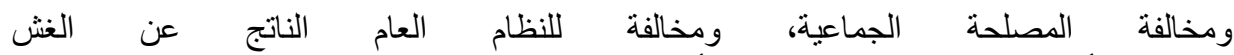

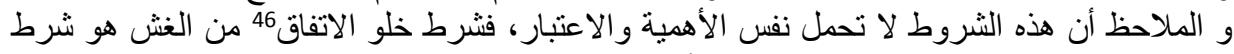

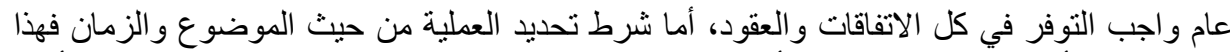

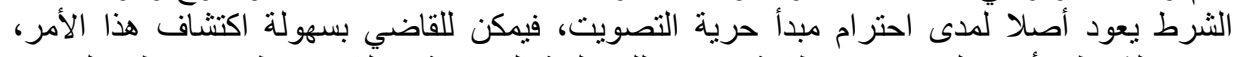

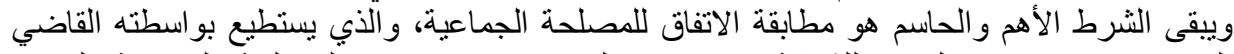

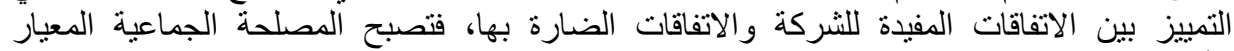

$$
\text { الأساسيز للتمييز بين الاتفاقات المشروعة وغير المشروعة. }
$$

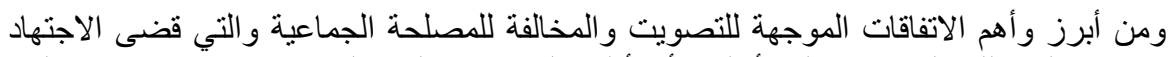

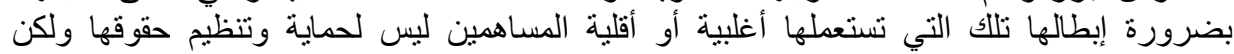
للإضر ار ببافي المساهمين وبالنالي الثركة.

\section{المطلب الثاني: اتفاقيات المساهمين والتعسف في استعمال الحق:}

ينتج التعسف في استعمال الحق عند ممارسة حق التصويت داخل الجمعيات العامة، فيمكن

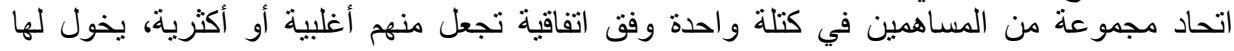

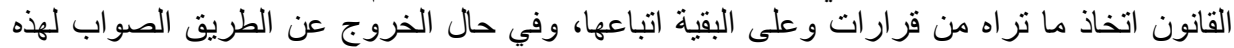

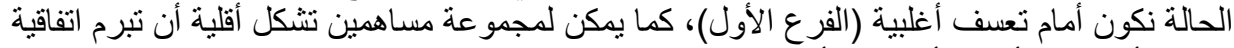

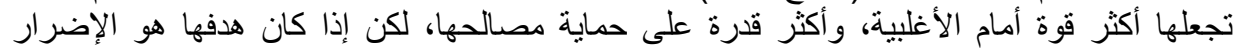
بالأغلبية وبالتالي بالثركة فنكون أمام تعسف الأقلية (الفرع الثانية. 
ينبغي التعرف أولا على تعسف الأغلبية تم ربطه بالاتفاقات التي قد تتصل بين المساهمين بهذا الثأن.

\section{أولا: مفهوم تعسف الأغلبية:}

إن قاعدة الأغلبية هي القاعدة الحاكمة لجميع القرارات التي تصدر عن مجلس الإدارة

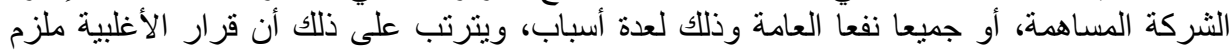

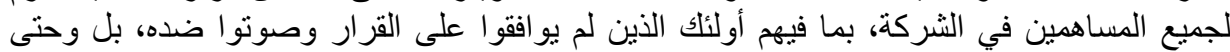
أولئك الذين تغيبوا عن حضور الاجتماع الذي صدر خلالهن القرار

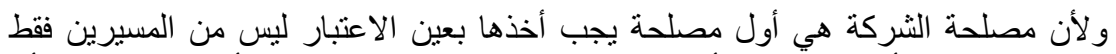

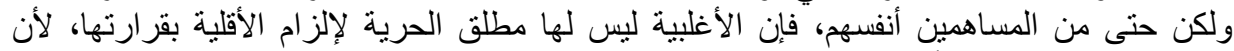
خضوع الجميع لقاعدة الأغلبية محكوم بتحقيق هدف مشنرك بـ بسوي بينهم.

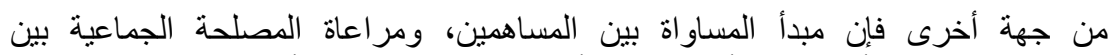

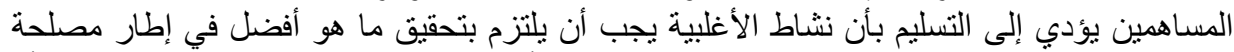

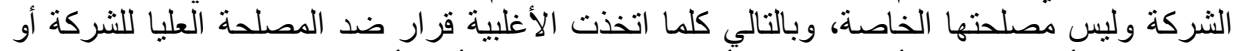
للإضرار بالأقلية كلما كنا أمام تعسف للأغلبية، و كلما كان للأقلية أو حتى للشركة التهار المطالبة بإبطال

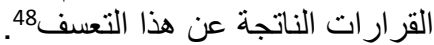

وقد ظهرت فكرة تعسف الأغلبية في العديد من البلدان ولا سيما في فرنسا، بين الحربين

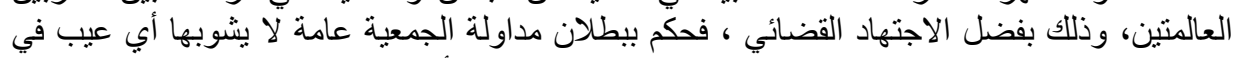

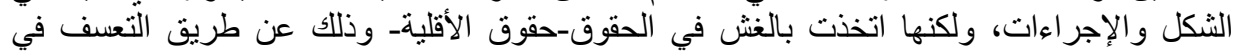

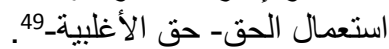

وكذلك تم الحكم بأن "أية مداولة متخذة طبقا للمصلحة العامة للشركة، لا بمكنها منح امتياز ات لفئة من المساهمين، وهي الأغلبية، وحرمان الأقلية"50.

$$
\text { وتلتها العديد من الأحكام في هذا الثأن. }
$$

\section{ثثانيا: اتفاقيات المساهمين كوسيلة لتعف الأغلبية:}

قد يتفق مجموعة من المساهمين حول توجيه حقوق التصويت التابعة لهم في اتجاه معين،

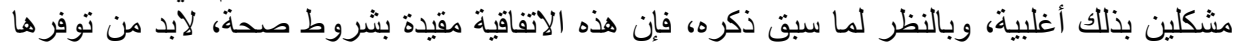

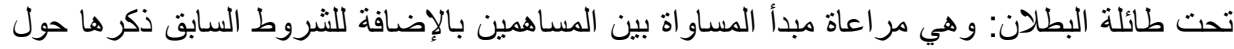
صحة هذا النوع من الاتفاقات.

$$
\text { وكصور عن هذا النوع من الاتفاقات و الذي قد بشكل تعسف نذكر: }
$$

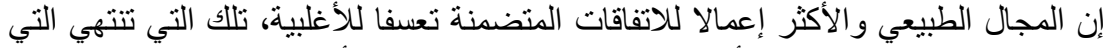

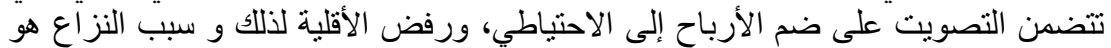

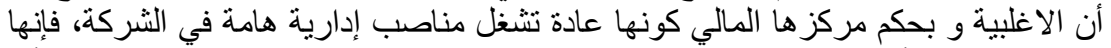

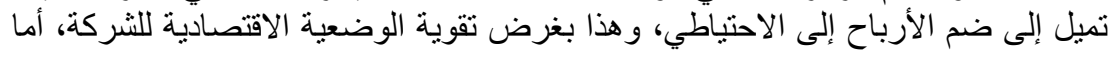


الأقلية فعادة ما يخالف رأيها ذلك، لأنها وبحكم وضعها المالي الضعيف، فهي تسعى دائما إلى تقرير توزيع الأرباح كل سنة.

و الفاصل هنا هو الهذف من هذا الاتفاق، فإذا كان هدفه تحقيق المصلحة الجماعية للمساهمين فلا مجال لإبطاله، وهو ما سار به الاجتهاد القضائي الفرنسيكان.

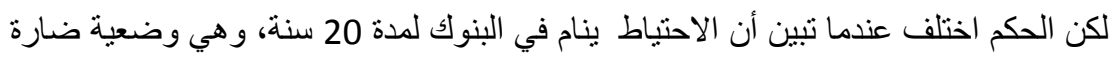

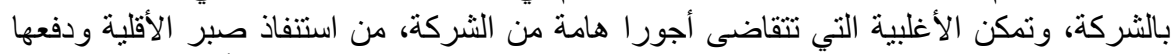

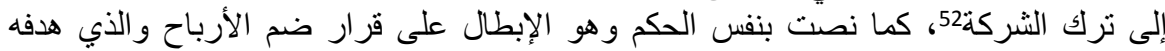

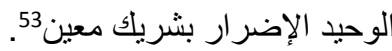

ومن جهة أخرى فإن هذه الاتفاقيات قد تحرم المساهم من إمكانية بيع أسهمه بقيمتها الحقيقية.

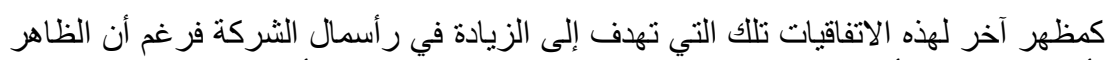

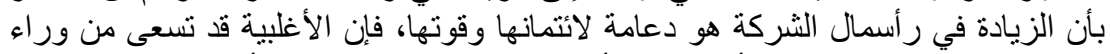

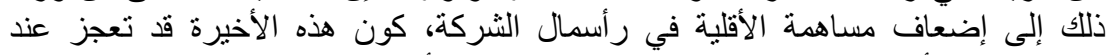

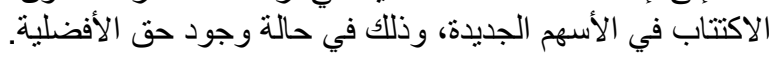

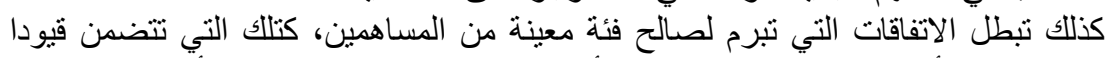

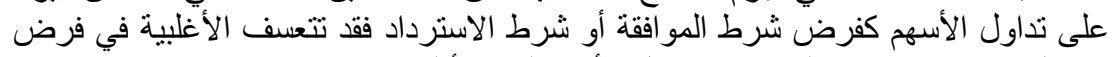
هذه القيود مما قد بيؤثر على حرية تداول الأسهم لاى الأقلية.

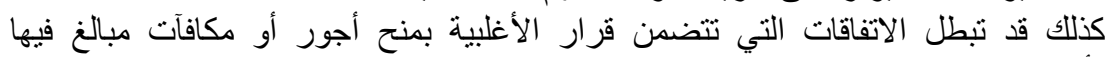

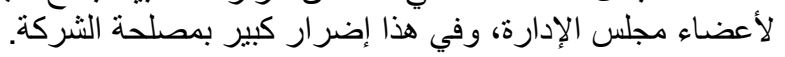

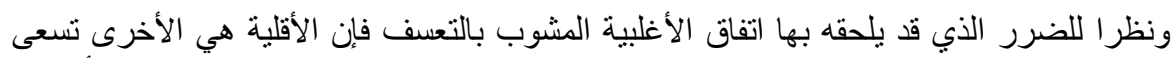

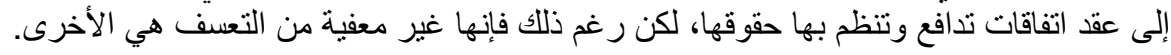

الفرع الثاني: اتفاقيات المساهمين وتعسف الأقلية:

كتعسف الأغلبية نتعرض أو لا لمفهوم التعف لدى الأقلية ثم لعلاقتها باتفاقات المساهمين.

\section{أولا: مفهوم تعسف الأقلية}

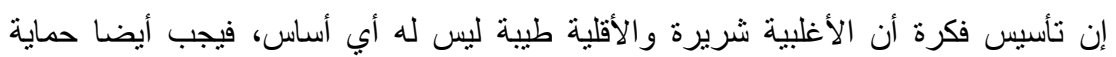

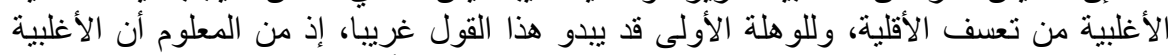

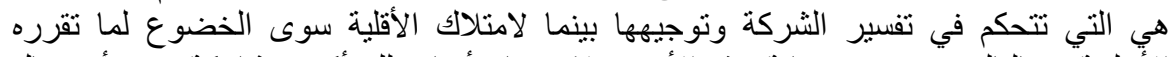

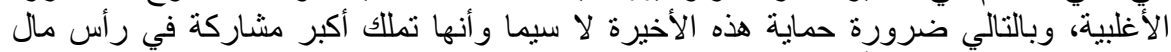
الشركة وبالتالي ستصدر أكثر.

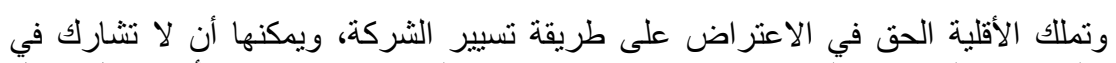

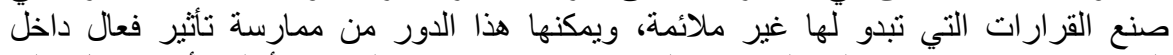

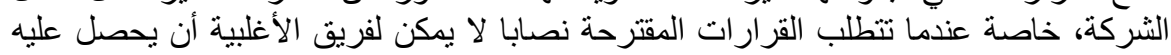

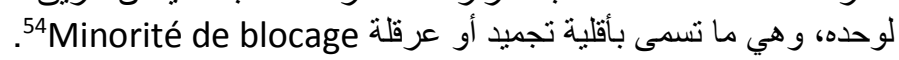


وقد عرف تعسف الأقلية بأنه فعل أو تصرف مجموعة من المساهمين الذين يحولون من

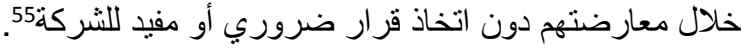

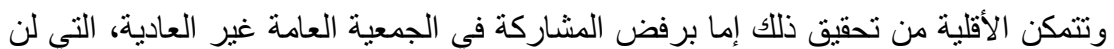

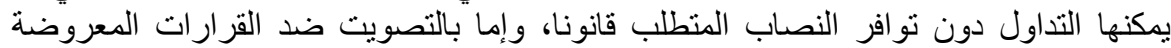
اللتصويت و التي تتطلب أغلبية التلثين.

وتعسف الأقلية قد يكون إيجابيائ Abus Positif ، ومثاله قيام الأقلية بمباثرة الدعاوى أمام

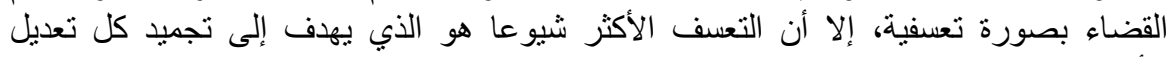
لكلانظمة وهو التعسف السلبي Abus négatif.

ويتفق تعسف الأقلية مع تعسف الأغلبية في كون كل منهما ينتج عن خرق الالتزامات الناتجة

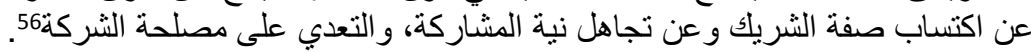

$$
\text { وكشروط لتقرير ها فإن: }
$$

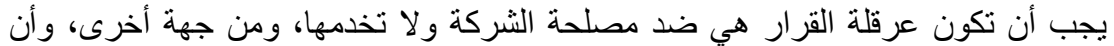

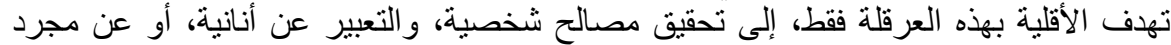

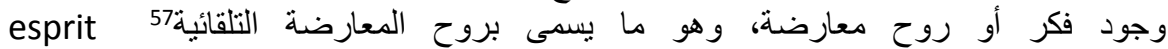

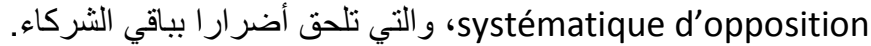

\section{ثانيا: اتفاقيات المساهمين كوسيلة لتعسف الأقلية:}

إن من أهم الوسائل التي تسمع للأقلية بتنظيم نفسها هي الاتفاقات فيما بينها، لا سيما في حالة الإنية التعسف سواء الإيجابي أو اللسلبي، وشأنها شأن تعسف الأغلبية فإن الاتفاقية التي تحوي تعسفا للأقلية و المخالفة لمصلحة الثركة تعتبر باطلة.

$$
\text { وتجد الحالة السابقة عدة تطييقات لها: }
$$

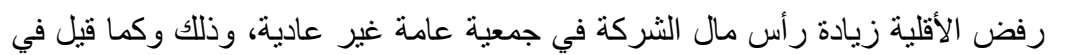

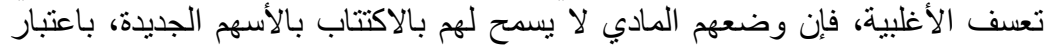

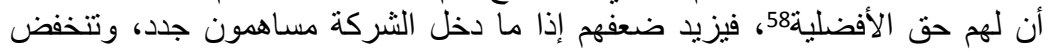

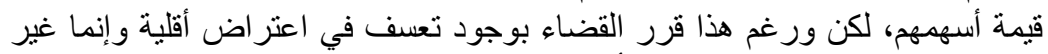

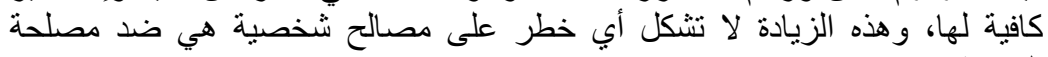
الثر كة.59. - مان.

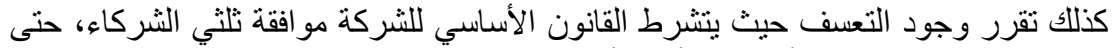

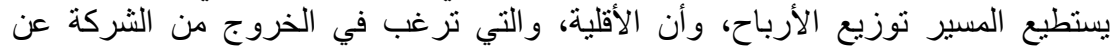

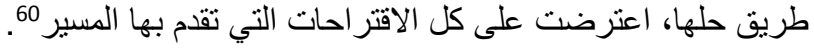

و على كل حال تبقى مصلحة الثركة وشروط صحة الاتفاقات بين المساهمين هي المعيار لقياس مدى صحة وقبول هذه الاتفاقات. 


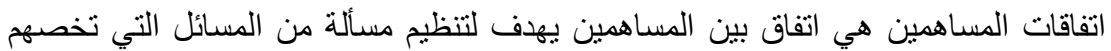

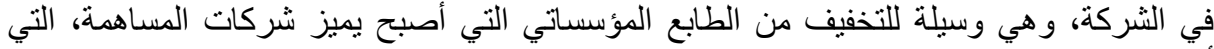
أصبحت تتظم بقو اعد صارمة وسئ.

وبالنظر لشروط صحة هذه الاتفاقات، فإنها تخضع في ذللك لأحكام العقود، من جهة، و المبادئ الأساسية

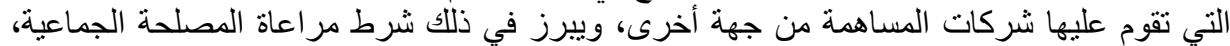

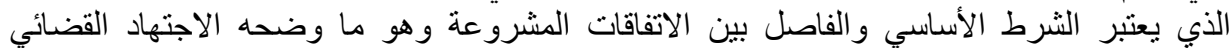
باعتباره المعالج الأساسي لهذّا النوع من الاتفاقات، مع غياب التنظيم التشريعي لهذه المسألة.

ومهما تكن هذه الاتفاقات مشروعة ومر اعية لمصلحة الشركة فإن عقد الشركة وقانونها الأساسي من أهم ما يجب أن تره اعيه هذه الاتفاقية منتوعة أبضا.

إن اتفاقيات المساهمين هي متتفس لهم، يمكنهم من التخلص من القيود التي أصبحت تحيط بقانون

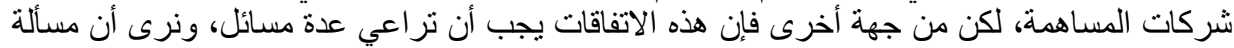

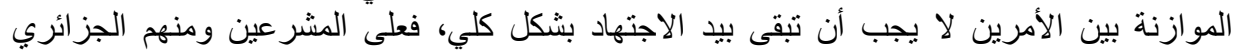

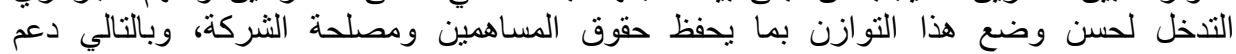
الاستقطاب لمثل هذه الثركات.

هوامش المادّة العلمية:

1 Dominique Schmidt, les droit de la minorité dans la société anonyme, Sirey, 1970, p63 note 1

2 أمينة غيموز، تعسف المساهمين في شركة المساهمة، دار الآفاق المغربية للنشر والتوزيع، الرباط،

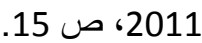

3غادة أحمد عيسى، الاتفاقيات بين المساهمين في الثركات المساهمة، المؤسسة الحديثة للكتاب،

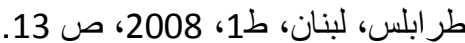

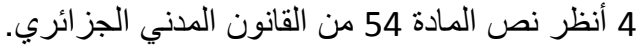

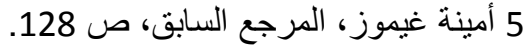

6Cass.com 21 mars 1977, JCP 1977, IV, p 135.

7 CA paris 10 ch.16 avril 1992, Bull joly 1992, p62 note Y, chaput

$$
\begin{aligned}
& 8 \text { أمينة غيموز، المرجع السابق، ص } 131 .
\end{aligned}
$$

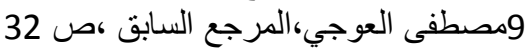

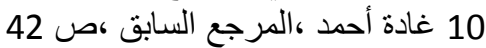

$$
\begin{aligned}
& 11 \text { أمينة غيموز، المرجد، المرع السابق، ص } 18 .
\end{aligned}
$$

12Cass.com 15 juin 1982, Jurisp, 503 note A-couret.

13J.P Bertel et M.Jeantin, Acquisition et fusion des societés commerciales litec, 1989, p 125.

14Y.Guyon, Traités des contrats, les société, Aménagements statutaires et convention entre associes, $3^{e}$ éd, LGDJ, 1997, p 190.

16Y.Guyon, op cit, p 290.

$$
\text { 15أمينة غيموز، المرجع السابق، ص } 26 .
$$

$$
\text { 17أمينة غيموز، المرجع السابق، ص } 81 .
$$

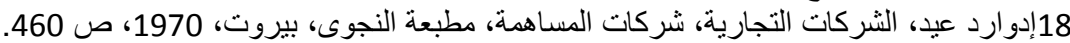
19Joseph Hamel, « Le droit spécial des société anonymes », dalloz librairie, paris, 1955, p p 331,332

20فؤاد سعدون عبد الله، إدارة الثركات المساهمة بين حقوق المساهمين القانونية وهيمنة مجلس الإدارة ورئيسه

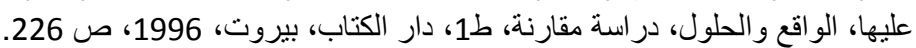


21Jeantin, "Les convention de vote », Rev.jur.com, nº spécial novembre 1990, p 124, et Viandier : observation sur les conventions de vote, JCP, 1986, I, 3253.

22Trib.com. paris $1^{\mathrm{er}}$ Aout 1974.

24Cass.com.11 juin 1965, Gaz.pal, 1965, 362.

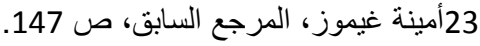

26Cass.com.8 fev 1982 : bull.lolly 1992, p 970.

28Les conflits d'interet dans la société anonyme, éd. Joly $1^{\text {er }}$ ed.L.G.D.J 1998, p 120.

29Cassversailles, 10 mars 1990, bull.Joly 1990, p 771.

Cass.com. 2 juin Dr.soc 1992, n 185, p 750.

Cass. 14 mars 1950, p 55.

30Tribcom, paris $1^{\text {er }}$ Aout 1974, op.cit

31Ca Versailles, 13 ch. $1^{\text {er }}$ décembre 1988, Bull.joly 1989, p 172 : « la révocation peut être immédiate, sans préarnis, sans motif et sans indemnité » 32CA Versailles, 10 mai 1990, bull.Joly 1990, p 771.

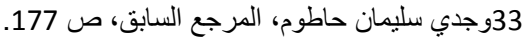

34G.Ripert, Les aspects juridiques du capitalisme moderne, 2éme édit 1951, L.G.D.J, p 15.253 35Souci.G, l'interet social dans le droit français des sociétés anonymes, these, Lyon II, 1974, p 67.

$$
\text { 36والمرجع نفسهان صاطوم، المرجع السابق، ص 164. } 162 .
$$

38Trib.com.de la seine 11 janvier 1938 journal de l'œuvre, S.1938.2.124.

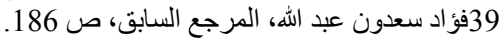

40Oppetit ,com, 10 jan 1972, JCP, 1972, II, 17134, Guyon, Trib.com, paris 4 mai 1981, JA,

1982, 7 cass.com 2 juillet 1985. Lustucru : Bull, Joly 1986, P 374 note w.L.B.

41La réforme du droit des sociétés par le D.L de 1935 et 1937, N 321, p 286.

42Dupuis.B, LA notion d'interet social, there paris XIII 2001, p 106 et Y.Guyon : traité des contrat les société, Aménagement statutaires et convention entre associes, 4éme ed L.G.D.J 99 p 366 et 5 éme ed 2002.

43Cass.com 10 mars 1950, JCP, 1950, II, 5.694, P.Bastan.cass.com 10 jan 1972, JCP, 1972, II, 17134.

45C.A. paris 30 juin 95, J.C.P.E 96 II 795 note Daigre

$$
\text { 44غادة أحمد عيسى، المرجع السابق، ص } 116 .
$$

46Trib.com. Seine 9 décembre 1920,

Trib.com 10 juin 1960 Bull. com 11227.

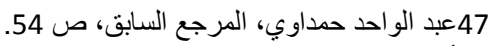

48أ. خلفاوي عبد الباقي، حق المساهم في رقابة شركة المساهمة، مذكرة ماجسنير تخصص قانون الأعمال، كلبة الحقوق،

49Trib.com.seine, 17 dec 1924, D.1925, 282.

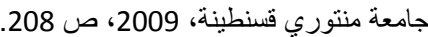

50Trib.CIV.Angers, 15 juillet 1930, DH, 1930, 580 .

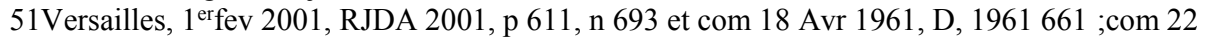
janv 1991, Bull joly 1991, p 389, n²123, M.Jeantin : Rev sociétés 1991, 345, JCP ed 1991, I, 61, $\mathrm{n}^{\circ} 5$, A.Viandier et J JCaussain, com 26Avr 1994, BRDA 12-1994, p3.

52Com 22 avr 1976, DP, 1977, 4, bousquet, 25, 1976, 479, Schmidt.

53Com 13 avr 1983, GP, 1983, 2, Pan, 239, Dupichot.

$$
54 \text { عبد الواحد حمداوي، المرجع السابق، ص } 81 .
$$

55Schmit Dominique, la responsabilité civile dans les relation de groupe de société, Rev. Soc 1981, p 155. 
56D. Schmidt, op.cit, p 181.

57Lyon 20 Dec 1984, D. 1986, p 506, note Reinhard, paris 26 juin 1990, J.C.P 1990, II, 21589 , note Germain, Rev sociétés 1990, p 613, note boizar.

59Lyon 20 Dec 1984, D 1986, 506, Y.Reinhard.

58 خلفاوي عبد الباقي، المرجع السابق، ص 226. 60Paris, 5 mai 1982, RDC, 1983, 244, Alfandari. 